\title{
Modeling Growth in Boys' Aggressive Behavior Across Elementary School: Links to Later Criminal Involvement, Conduct Disorder, and Antisocial Personality Disorder
}

\author{
Cindy M. Schaeffer \\ University of Maryland, Baltimore County
}

\author{
Hanno Petras and Nicholas Ialongo \\ Johns Hopkins Bloomberg School of Public Health
}

\author{
Jeanne Poduska and Sheppard Kellam \\ American Institutes for Research
}

\begin{abstract}
The present study used general growth mixture modeling to identify pathways of antisocial behavior development within an epidemiological sample of urban, primarily African American boys. Teacher-rated aggression, measured longitudinally from 1st to 7 th grade, was used to define growth trajectories. Three high-risk trajectories (chronic high, moderate, and increasing aggression) and one low-risk trajectory (stable low aggression) were found. Boys with chronic high and increasing trajectories were at increased risk for conduct disorder, juvenile and adult arrest, and antisocial personality disorder. Concentration problems were highest among boys with a chronic high trajectory and also differentiated boys with increasing aggression from boys with stable low aggression. Peer rejection was highest among boys with chronic high aggression. Interventions with boys with distinct patterns of aggression are discussed.
\end{abstract}

Antisocial behavior is among the most common and serious mental health problems presently faced in the United States (Kessler et al., 1994). Conduct disorder is one of the most prevalent disorders of childhood (3\%-10\%; Lewinsohn, Hops, Roberts, Seeley, \& Andrews, 1993) and is associated with an array of other problems, including school failure, substance abuse, and adult psychiatric disorder (Capaldi \& Stoolmiller, 1999; Krueger, Caspi, Moffitt, \& Silva, 1998; Lambert, Wahler, Andrade, \& Bickman, 2001; Loeber, Burke, Lahey, Winters, \& Zera, 2000). Prevalence rates for antisocial personality disorder in community populations are also high (2\%-3\%; Moran, 1999; Reiger, Farmer, Rae, \& Myers, 1993) and may be even higher in urban ethnic-minority populations (Turner \& Gil, 2002). In addition, juvenile and adult

Cindy M. Schaeffer, Department of Psychology, University of Maryland, Baltimore County; Hanno Petras and Nicholas Ialongo, Department of Mental Health, Johns Hopkins Bloomberg School of Public Health; Jeanne Poduska and Sheppard Kellam, American Institutes for Research.

This research was supported by National Institutes of Mental Health Grants RO1 MH42968 (Sheppard Kellam, Principal Investigator) and T-32 MH18834 (Nicholas Ialongo, Principal Investigator) and Centers for Disease Control and Prevention Grant R49/CCR318627-03. We thank the Baltimore City Public Schools for their continuing collaborative efforts and the parents, children, teachers, principals, and school psychologists and social workers who participated. We also express our appreciation to Scott Hubbard and Sharon Lambert, who made significant contributions to the data analysis and editing of the manuscript, and to Bengt Muthén, who provided valuable consultation on statistical modeling techniques.

Correspondence concerning this article should be addressed to Cindy M. Schaeffer, Department of Psychology, 1000 Hilltop Circle, University of Maryland, Baltimore County, Baltimore, Maryland 21250. E-mail: cschaeff@umbc.edu criminality is detrimental to the mental health of victims (New \& Berliner, 2000; Robinson \& Keithley, 2000) and causes high financial costs to society related to victimization (i.e., healthrelated costs, lost productivity), law enforcement, and the maintenance and expansion of the correctional system (Britt, 2000; Cohen \& Miller, 1998).

Childhood aggressive behavior has been identified as the most significant antecedent of antisocial behavior in adolescence and adulthood (Loeber \& Hay, 1997). Yet the available evidence also suggests that a substantial proportion of those children who display high levels of aggressive behavior in childhood do not manifest antisocial behavior in adolescence or adulthood (Maughan \& Rutter, 1998). Indeed, there appear to be "desisters" as well as "persisters" (McCord, 1983). Moreover, a considerable number of children appear to be "late starters" (Moffitt, 1993), engaging in average levels of aggressive behavior in the early childhood years but proceeding to engage in serious antisocial behavior in adolescence and adulthood. The accruing evidence of these divergent pathways to serious antisocial behavior has generated considerable interest in uncovering additional pathways and in understanding the child, family, school, and neighborhood factors that can identify early youths on specific aggression trajectories. It is important to discriminate various pathways early in the developmental course so that the limited resources available for preventive and intervention efforts may be more precisely targeted.

\section{Models of Antisocial Behavior Development}

Several models of antisocial behavior (i.e., Loeber et al., 1993; Moffitt, 1993; Patterson, DeBaryshe, \& Ramsey, 1989) have proposed distinct developmental trajectories toward later antisocial outcomes. Loeber et al. (1993) outlined three pathways leading to 
different types of delinquency and criminal involvement: overt (i.e., high levels of aggression in childhood and violence in adolescence and adulthood), covert (i.e., covert antisocial acts in childhood and nonviolent, property crimes later in development), and authority conflict (i.e., a progression from stubborn behavior, deviance, and authority avoidance to later status offending). Patterson et al.'s (1989) model argues for two distinct pathways toward adult criminality: those of early starters (i.e., involving coercive parenting, school failure, and antisocial behavior problems starting in childhood) and late starters (i.e., involving poor parental monitoring, oppositionality, and deviant peer involvement starting in early adolescence). Moffitt's (1993) model also proposes two mutually exclusive subgroups of antisocial youth: life-coursepersistent offenders, who show high levels of aggression throughout development and continue to be violent as adults, and adolescence-limited offenders, who engage in nonviolent forms of antisocial behavior only during the teen years.

More recently, Loeber and Stouthamer-Loeber (1998) proposed five distinct subtypes to account for research suggesting a high degree of heterogeneity in antisocial behavior development. They proposed two types of life-course-persistent aggressive youths, one with a preschool onset of aggression and comorbid attentiondeficit/hyperactivity disorder (ADHD) and one with a middlechildhood onset of aggression without ADHD. They also proposed two limited-duration aggression groups, one whose initially high level of aggression desists in elementary school and another whose aggression desists in late adolescence or early adulthood. The final group, late-onset offenders, is thought to be composed of those youths who show no antecedent problems in aggression but who develop antisocial behavior problems in late adolescence or early adulthood.

Despite differences in terminology and emphasis, each model identifies from two to five distinct groups of antisocial youth with different behavioral patterns, risk factors, and prognoses for desistence from antisocial behavior as adults. Each model proposes one or two chronic groups (i.e., Patterson et al.'s [1989] early starters; Moffitt's [1993] and Loeber and Stouthamer-Loeber's [1998] life-course-persistent groups) whose early and persistent aggression is likely to be related to a biological or genetic vulnerability that is exacerbated by poor parenting and early school failure. Each model also identifies one or two less severe groups (i.e., Moffitt's adolescent-limited group, Patterson et al.'s late starters, and Loeber and Stouthamer-Loeber's limited duration pathways) whose antisocial behavior starts later, is less aggressive, is more sporadic, and stems from later socialization experiences such as deviant peer affiliations in early adolescence. Also implicit in each model is the assumption that there is at least one other group of youths who do not exhibit problems with antisocial behaviors. These models have helped to shift the study of youth antisocial behavior away from a variable-centered focus on describing broad predictors of behavior toward a more personcentered focus emphasizing individual differences in development (Magnusson, 1998).

\section{Modeling Studies of Individual Differences in Antisocial Behavior Development}

Various methodological techniques have been used to determine individual differences in longitudinal patterns of antisocial behav- ior. One technique is to make subjective classifications of individuals on the basis of their progression on variables of interest over time using empirically or theoretically defined cutoff scores. For example, evidence for Loeber's overt, covert, and authority acceptance classifications has been found in various longitudinal samples of antisocial boys by assigning youths with different offending patterns to the pathways and externally validating those assignments on distal criminal outcomes (Loeber, Green, Keenan, \& Lahey, 1995; Loeber, Keenan, \& Zhang, 1997; Loeber, Wei, Stouthamer-Loeber, Huizinga, \& Thornberry, 1999; Tolan \& Gorman-Smith, 1998). Similarly, support for Moffitt's (1993) model has been found with subjective classification of aggressive and criminal behavior in longitudinal samples from the Dunedin, New Zealand, and Oregon Youth studies (Moffitt \& Caspi, 2001; Moffitt, Caspi, Harrington, \& Milne, 2002; Patterson, 1996; Patterson, Forgatch, Yoerger, \& Stoolmiller, 1998).

Although subjective assignment of youths to various developmental trajectories has heuristic value, this method is fraught with problems as well. Subjective classification does not allow for empirical testing and may over- or underassign youths to various trajectories while failing to identify other trajectories entirely. An alternative method for identifying developmental patterns in longitudinal data is to use latent class growth modeling techniques to empirically define distinct subgroups within a sample (B. Muthén, 2000; Raudenbush, 2000). These techniques, which treat group membership as an unobserved variable, have been used to describe individual differences in development for a range of behaviors, including reading achievement (e.g., Crijnen, Feehan, \& Kellam, 1998), coping strategies (e.g., Sandler, Tein, Mehta, Wolchik, \& Ayers, 2000), substance use (e.g., Curran, Muthén, \& Harford, 1998; White, Xie, Thompson, Loeber, \& Stouthamer-Loeber, 2001), and aggression (e.g., B. Muthén et al., 2002).

Several groups of researchers have used latent class growth modeling to classify antisocial boys on the basis of their longitudinal behavioral patterns (Broidy et al., 2003; Fergusson \& Horwood, 2002; Maughan, Pickles, Rowe, Costello, \& Angold, 2000; Nagin \& Tremblay, 1999; Shaw, Gilliom, Ingoldsby, \& Nagin, 2003). Taken together, the results from these longitudinal studies suggest that there are empirically identifiable subgroups of youths with distinct developmental trajectories of antisocial behavior. Those studies that modeled aggression over time identified different numbers of trajectories, but the trajectories were otherwise similar. Each study identified from one to two normative subgroups (about $60 \%$ of boys) that never showed serious problems with aggression and were not at increased risk for later criminal behavior. These studies also identified two groups of boys with sustained problems in antisocial behavior over time: a chronic group (4\%-12\% of boys) whose aggressive behavior was consistently high throughout development and a high but desisting group (20\%-28\% of boys) whose aggression started at a high level but decreased over time. Across samples, these aggressive trajectories were associated with later antisocial and criminal behavior in adolescence (Maughan et al., 2000; Nagin \& Tremblay, 1999). Although Fergusson and Horwood (2002) used criminal offending to define developmental trajectories, making it difficult to directly compare their results to those of studies that used aggressive behavior, their findings do suggest that there might be additional identifiable groups of boys who show an adolescent onset of antisocial behavior with no antecedent problems in aggression. 
These modeling studies provide support for some of the antisocial pathways hypothesized by current theoretical models, but they also indicate a need for further model refinement. For example, Nagin and Tremblay (1999) identified a group of boys not hypothesized in theoretical models, those with moderate early aggressive behavior problems who gradually desisted and showed no later problems with antisocial behavior (i.e., the moderate desisters). In addition, some hypothesized subgroups have yet to be empirically identified, such as Loeber and Stouthamer-Loeber's (1998) second life-course-persistent group, the childhood-onset group (whose aggression is thought to begin in middle childhood rather than preschool).

\section{Limitations of Existing Longitudinal Research on Antisocial Behavior Development}

These large-scale longitudinal studies selected community samples of youths and used latent class growth modeling techniques to empirically (rather than subjectively) assign youths to specific trajectories of antisocial behavior. However, these studies have several noteworthy limitations. First, the semi-parametric groupbased (SPGB; Nagin \& Tremblay, 1999) modeling approach used in all of these studies assumes that pathways are composed of individuals homogenously, an assumption that may not be valid for highly variable behaviors such as aggression, in which we might expect more variability in problematic than in low-risk classes (B. Muthén, 2000). Second, none of these studies examined the level of heterogeneity in the association between trajectory classes, risk factors for trajectory membership, and distal outcomes within the models themselves (i.e., estimates of the association between developmental trajectories and distal outcomes were not corrected for the uncertainty of the trajectory class assignments), and therefore they may have over- or underestimated these associations. Finally, with the exception of the Pittsburgh Youth Study sample reported in Broidy et al. (2003), all of the studies used samples in which the majority of youths were of European descent; thus, the extent to which findings from these studies pertain to youths of other racial and ethnic groups is uncertain.

\section{Rationale and Goals for the Present Study}

In the present study, we had several goals. The first was to use latent class growth modeling techniques to identify trajectories of aggressive behavior among a community sample of urban, predominantly African Americans boys for whom teacher reports of aggressive behavior were available from Grades 1-7. On the basis of the theoretical and empirical work reviewed above, we expected to find five distinct groups of boys with different trajectories: a chronic high group (i.e., "early starters" or "persisters") whose aggressive behavior would already be elevated upon entry to first grade; a childhood-onset group whose aggressive behavior would start low in early elementary school but would increase over time; a declining group whose initially high levels of aggression would decline by middle school (i.e., "desisters"); a "late-starter" group whose aggression would escalate beginning in late elementary or middle school; and a group of boys whose aggressive behavior would remain consistently low over the course of Grades 1-7.

A second goal was to evaluate the utility of these classifications in predicting later adolescent and adult antisocial behavior. We expected, consistent with Loeber and Stouthamer-Loeber's (1998) model regarding life-course-persistent patterns of aggression, that youths with a chronic high or increasing (childhood-onset) trajectory would be at increased risk relative to nonaggressive boys for later antisocial outcomes, with those youths in the chronic aggression category at highest risk. Regarding boys with limited-duration patterns of aggressive behavior, we hypothesized that late starters in our sample would be at increased risk for antisocial outcomes relative to nonaggressive boys, whereas desisters would demonstrate no increased risk.

Our third goal was to explore risk factors that can help to predict which boys will experience which pathways, particularly those factors that can differentiate early in the developmental trajectory boys with increasing patterns of aggression from nonaggressive boys and persisters from desisters. We were particularly interested in exploring risk factors that could be assessed within the school setting. At present, schools are the primary setting in which preventive interventions occur. As such, indicators that can be collected inexpensively and quickly within the school setting would allow for the cost-effective and efficient identification of at-risk groups. Once identified, youths progressing along a high-risk trajectory could be targeted to receive the limited prevention resources available. To these ends, we decided to focus on teacherrated concentration problems and peer rejection as two predictors that might aid early interventionists in more precisely targeting youths for preventive interventions.

We hypothesized that concentration problems and peer rejection in the presence of high levels of aggressive/disruptive behavior at the entrance to first grade would promote the persistence of aggressive/disruptive behavior over time and heighten the risk of later antisocial behavior in adolescence and adulthood. Thus, we expected that "persisters," those boys evidencing chronically high aggression over the course of childhood and early adolescence, would have significantly higher levels of concentration problems and peer rejection than would "desisters," those youths who display high levels of aggressive behavior early on in development but whose aggression decreases over time and who are at low risk for antisocial behavior in adolescence and adulthood. There is considerable empirical (Jensen, Martin, \& Cantwell, 1997; Lahey, McBurnett, \& Loeber, 2000; Moffitt, 1990; Satterfield \& Schell, 1997) and theoretical (e.g., Loeber et al., 1993; Moffitt, 1993; Patterson et al. 1989) evidence linking ADHD and concentration problems to chronic antisocial behavior patterns. In terms of potential mechanisms, concentration problems may make demand/ compliance bouts more likely (Patterson, Reid, \& Dishion, 1992), which, in turn, lead to more frequent coercive child behavior management on the part of parents and teachers and more sustained levels of aggressive/disruptive behavior over development. Peer rejection is another common correlate of chronic aggressive behavior problems (Haselager, Van Lieshout, Riksen-Walraven, Cillessen, \& Hartup, 2002; Hektner, August, \& Realmuto, 2000; Lewin, Davis, \& Hops, 1999; D. Schwartz, 2000) and may serve to hasten the aggressive/disruptive child's drift into a deviant peer group, where antisocial behavior is reinforced, thus canalizing the pathway to antisocial behavior (Deater-Deckard, 2001; French, Conrad, \& Turner, 1995; Hektner et al., 2000; Patterson et al., 1992). We also expected that the chronic high aggression group would have higher levels of concentration problems and 
rejection by classmates than would boys in the low aggression group.

We also predicted that boys with increasing aggression (childhood-onset subtype) would show higher levels of concentration problems and peer rejection relative to nonaggressive boys at entrance to first grade. In formulating this hypothesis, we drew on Patterson et al.'s (1992) conceptualization of the development of antisocial behavior among late starters. Typically, late starters are thought of as youth who begin exhibiting antisocial behavior in adolescence. However, the same processes and principles elaborated by Patterson et al. in the development of antisocial behavior among late starters could certainly be at work earlier in development (e.g., in the elementary school years). Patterson et al. posited that late starters are vulnerable to the impact of a disruption in parent discipline and/or exposure to a deviant peer group because of marginal "social survival skills" in the academic and peer domains. For example, first graders who possess limited social problem-solving skills may be at risk for peer rejection, which in turn may accelerate their "drift" into a deviant peer group later in development, where they are reinforced for antisocial behavior. It may also be the case that attention/concentration problems early in first grade serve to make children vulnerable later in the life course to the development of antisocial behavior. More specifically, attention/concentration problems at home and/or in the classroom may increase the likelihood of demand/compliance bouts with parents and/or teachers. Such bouts may then lead to more coercive and inconsistent forms of discipline on the part of parents and teachers. Inconsistent and coercive discipline may then set the stage for the development of antisocial behavior. The above reasoning led us to hypothesize that among those children who display low levels of aggressive/disruptive behavior early in their elementary school careers, the higher the level of peer rejection and/or concentration problems, the more likely it is that they will manifest antisocial behavior later in their development.

The present study expands upon previous longitudinal work in several important ways. First, unlike most previous studies examining primarily White urban (e.g., Fergusson \& Horwood, 2002; Nagin \& Tremblay, 1999; Shaw et al., 2003) and White rural (e.g., Maughan et al., 2000) youths, the present study used a longitudinal sample composed primarily of African American urban youths, a sample selection consistent with the U.S. Surgeon General's call for more mental health research among ethnic-minority populations (U.S. Public Health Service, 2001). Second, the present study used an epidemiologically defined population representative of all youths entering first grade in 19 public schools within five urban areas defined by census tract data and vital statistics. Accordingly, the present study allows for generalization to similar populations of students entering school from urban neighborhoods with multiple problems (i.e., high rates of poverty, unemployment, and crime). Third, the present study included a range of both psychiatric and criminological distal outcomes (diagnoses of conduct disorder [CD] and antisocial personality disorder [ASPD], juvenile arrests, and adult arrests) measured at a much later point in development (young adulthood), thereby providing strong external validity for the identified trajectories and spanning several important periods for youth antisocial behavior development. Finally, the present study employed the newest generation of latent growth modeling techniques, general growth mixture modeling (GGMM; B. Muthén \& Muthén, 2000), to address the methodological lim- itations (i.e., assumption of invariance between classes and time points, uncorrected estimates of covariates and distal outcomes) of previous modeling studies.

\section{Method}

\section{Participants}

Participants included 297 males who were first assessed at age 6 as part of an evaluation of two school-based, universal preventive interventions targeting early learning and aggression in the first and second grades (Dolan et al., 1993; Kellam et al., 1991) in 19 Baltimore City public schools. ${ }^{1}$ These 297 males were members of the control group within the evaluation design. The 19 schools were drawn from five geographic areas within the eastern half of the city that were defined by census tract data and vital statistics obtained from the Baltimore City Planning Office. The five areas varied by ethnicity, type of housing, family structure, income, unemployment, violent crime, suicide, and school dropout rates. However, each area was defined so that the population within its borders was relatively homogenous with respect to each of these characteristics.

Special education and gifted classrooms were excluded from the pool of potential classrooms in light of the fact that the preventive interventions targeted regular or mainstream classrooms. In schools with three or fewer regular first-grade classrooms, all classrooms participated, whereas in larger schools, three first-grade classrooms were randomly selected for inclusion in the study. Children had been randomly assigned to classrooms prior to the assignment of classrooms to intervention conditions. Schools were randomly assigned to either an intervention or control condition within a geographic area. In all analyses, standard errors were corrected to reflect the fact that individual participants were clustered within classes and within schools.

A total of 343 male control participants were originally available within the 19 participating Baltimore City public schools in first grade. Forty-six of these 343 control boys did not have a teacher rating from the fall semester of first grade and, consequently, were not included in the analyses for this article. ${ }^{2}$ Of the resulting sample of 297 boys, $58.2 \%$ were African American, $40.7 \%$ were of European American heritage, and $1.0 \%$ were of some other ethnicity (American Indian or Hispanic). At entrance into first grade, the boys had a mean age of 6.2 years $(S D= \pm 0.34)$. Forty-three percent of the children received free or reduced price school lunches, a proxy for family income. There were no differences in terms of free lunch status, ethnicity, age, or standardized achievement test scores between the 46 boys with no teacher data in the fall of first grade and the 297 boys with teacher data.

Of the 297 control males with a fall-semester first-grade teacher rating, 22 refused to participate in the age 19-20 follow-up, 10 had died prior to the follow-up as confirmed by a search of the National Death Index and/or

\footnotetext{
${ }^{1}$ Girls were excluded from the analysis for several reasons. First, much of the theoretical and empirical literature is based on boys. To do justice to the extant models of aggression for girls would have required a substantial increase in manuscript length. Second, our growth mixture modeling work with girls suggests the need for unique methods to deal with the high number of structural zeros (i.e., high numbers of girls with very low aggression). Methodologists (Carlin, Wolfe, Brown, \& Gelman, 2001; Olsen \& Schafer, 2001) have discussed possible approaches to dealing with the issue of structural zeros; however, these approaches are still in development. It is our intent to report separately on the growth of aggression in girls once these methodological issues are resolved.

${ }^{2}$ These cases would have been excluded by the Mplus software used in these analyses. The algorithm used in the software excludes cases that are missing covariates. In all cases, those boys missing teacher-rated aggression in the fall semester of first grade also were missing data on covariates.
} 
an immediate family member or friend, and the remaining 60 young adults either failed to respond to repeated requests for an interview or were unable to be located during the fielding period. Thus, 205 boys (63\% African American, 36\% European American, and 1\% American Indian or Hispanic) contributed data for variables from the age 19-20 follow-up. ${ }^{3}$ As to differences between those 205 males with teacher ratings from the fall semester of first grade who completed the age 19-20 follow-up and those 92 males with such ratings for whom the age 19-20 follow-up data were missing, no differences were found in terms of ethnicity, free lunch status, reading and math achievement, child's ratings of anxiety and depression, and teacher ratings of aggressive behavior and concentration problems.

\section{Assessment Design}

Data for this report were gathered in the fall and spring semesters of the first and second grades, in the spring semesters of the third through seventh grades, and at the age 19-20 follow-up assessment. The data gathered in the first-grade assessments included teacher reports of child aggressive/ disruptive behavior, attention/concentration problems, and peer rejection. Data on free lunch eligibility were also collected in first grade. Teacher reports of child aggressive/disruptive behavior were collected annually or semiannually in Grades 1-7. At age 19-20, a follow-up structured clinical interview was used to ascertain whether the participant met criteria for conduct disorder and antisocial personality disorder, and juvenile and adult adjudication records were obtained.

\section{Measures}

Teacher Observation of Classroom Adaptation-Revised (TOCA-R; Werthamer-Larsson, Kellam, \& Wheeler, 1991). Teacher ratings of aggressive/disruptive behavior, attention/concentration problems, and peer rejection were obtained in the fall and spring semesters of the first and second grades using the TOCA-R. Thereafter, teacher ratings of aggressive/disruptive behavior using the TOCA-R were collected annually in the spring in Grades 3-7. Thus, although the first-grade variables were rated by the same teacher, each subsequent year a different teacher provided ratings of aggression for the child.

The TOCA-R is a structured interview with the teacher that is administered by a trained assessor. Teachers respond to 36 items pertaining to the child's adaptation to classroom task demands over the past 3 weeks. Adaptation is rated by teachers on a 6-point frequency scale $(1=$ almost never $;=$ almost always). The Authority Acceptance subscale, measuring aggressive/disruptive behaviors, includes the following items: "breaks rules," "harms others and property," "breaks things," "takes others' property," "fights," "lies," "trouble accepting authority," "yells at others," "stubborn," and "teases classmates." The coefficient alphas for the Authority Acceptance subscale ranged from .92 to .94 over Grades 1 through 7 , or ages $8-13$. The 1 -year test-retest intraclass reliability coefficients ranged from .65 to .79 over Grades $2-3,3-4,4-5,5-6$, and $6-7$. Scores on the Authority Acceptance subscale were significantly related to the incidence of school suspensions within each year through Grades 1-7 (i.e., the higher the score on aggressive behavior, the greater the likelihood of being suspended from school that year).

Regarding the TOCA-R's Attention-Concentration Problems subscale (e.g., "pays attention," "easily distracted"), Werthamer-Larsson et al. (1991) reported alphas of .91 and .83 in first grade. In terms of concurrent validity, each single unit of increase in teacher-rated attention/ concentration problems was associated with a twofold increase in risk of teacher perception of the need for medication for such problems. Teacher ratings of peer rejection were based on a single item, "rejected by classmates," with 1 indicating total acceptance and 6 representing total rejection. The 4-month intraclass correlation coefficient for this item was .74, and it correlated significantly with peer nominations (not reported in this study) for the questions "Which kids don't you like?" $(r=.43)$ and "Which kids are your best friends?" $(r=-.58)$.

$C D$ and ASPD diagnoses. As part of a larger telephone interview at age 19-20, a scale was developed and administered to determine whether the participant met criteria from the fourth edition of the Diagnostic and Statistical Manual of Mental Disorders (DSM-IV; American Psychiatric Association, 1994) for ASPD and CD. The questions composing the scale were keyed to $D S M-I V$ criteria and the diagnoses derived in accord with those criteria. To reduce the likelihood of socially desirable responses, we asked participants to maintain their own count of "yes" responses as opposed to responding "yes" or "no" to the interviewer's questions. To ensure against the respondents' losing track of the count, they were asked to have a pencil and sheet of paper available to mark down the number of "yes" responses. In addition, the questions were divided into three sections, and a count of "yes" responses was obtained by the interviewer at the end of each section. In terms of concurrent validity, relative to those who did not meet criteria for ASPD or CD, male participants with an ASPD or CD diagnosis were between three and four times more likely to have a juvenile or adult criminal record (for ASPD, the odds ratio $[\mathrm{OR}]=3.40$, and the $95 \%$ confidence interval $[\mathrm{CI}]=2.38-4.83$; for $\mathrm{CD}$, the $\mathrm{OR}=3.21$, and the $95 \% \mathrm{CI}=2.29-4.49$ ).

Juvenile and adult adjudication records. Juvenile police and court records also were obtained throughout the follow-up period to determine the frequency and nature of police contacts and criminal convictions during adolescence. Juvenile records were updated after all participants had aged out of the juvenile court system (i.e., after everyone in the sample had reached their 18th birthday) and thus represent complete juvenile court data for this sample. Adult court records were obtained at the time of the young-adult follow-up interview when participants were, on average, 20 years of age. For the present study, both juvenile and adult court records were treated as binary variables (i.e., presence or absence of a record).

Eligibility for free lunch. Eligibility for a free school lunch upon entry into first grade was chosen as a proxy for family income in the present study and was used as a control variable in all analyses. Conceptually, eligibility for free lunch is likely to be a proxy variable for a range of economic and other stressors operating at the family and neighborhood levels. Previous research has demonstrated that free lunch eligibility correlates highly with family income and other traditional measures of socioeconomic status (Ensminger et al., 2000). Eligibility was treated as a binary variable (i.e., eligible or not eligible). In the present study, free lunch status had a strong negative correlation with parent education status measured in fourth grade.

Race is an important factor to consider in studies of antisocial behavior given that African American youth are disproportionately represented in the juvenile justice system (Poe-Yamagata \& Jones, 2000; Snyder \& Sickmund, 1999) and may be rated higher by teachers on externalizing behavior problems (Zimmerman, Khoury, Vega, \& Gil, 1995). Although we originally planned to examine race as a covariate in our models, we were unable to do so because of the confounding of race and poverty in our sample. African American boys were significantly more likely to be receiving a free school lunch in first grade than were Caucasian boys $(64 \%$ vs. $15 \%), \chi^{2}(1, N=297)=68.47, p<.01$. African American boys in our sample had significantly higher teacher ratings of aggression at only 3 of the 9 time points examined, whereas boys receiving a free or reduced-price school lunch had significantly higher ratings of aggression on 8 of the 9 time points. It should be noted that when racial differences on aggression did emerge, they were quite small (approximately one third of a standard deviation). In regard to distal outcomes, both African American boys and

${ }^{3}$ Because full-information maximum-likelihood estimation was used in all analyses (under the assumption that the data were missing at random), parameter estimates were based on all available time points for a given case. Thus, the sample size for all analyses was 297. 
Table 1

Observed Descriptive Statistics of Teacher-Rated Aggression

\begin{tabular}{llccrr}
\hline Semester and grade & $M$ & $S D$ & Variance & Skewness & Kurtosis \\
\hline Fall, Grade 1 & 2.03 & 1.05 & 1.09 & 1.27 & 1.27 \\
Spring, Grade 1 & 2.14 & 0.95 & 0.90 & 1.16 & 1.54 \\
Fall, Grade 2 & 1.94 & 1.02 & 1.03 & 1.27 & 1.02 \\
Spring, Grade 2 & 2.20 & 1.10 & 1.20 & 0.05 & 0.70 \\
Spring, Grade 3 & 2.40 & 1.24 & 1.54 & 1.21 & 1.36 \\
Spring, Grade 4 & 2.19 & 1.07 & 1.14 & 0.70 & -0.39 \\
Spring, Grade 5 & 2.42 & 1.17 & 1.38 & 0.98 & 0.28 \\
Spring, Grade 6 & 2.25 & 1.17 & 1.37 & 0.65 & -0.30 \\
Spring, Grade 7 & 2.32 & 1.08 & 1.18 & & \\
\hline
\end{tabular}

boys receiving free school lunches in first grade were significantly more likely to be arrested as juveniles and as adults and to meet criteria for CD and ASPD. Given these confounds, race was not included in the analyses. ${ }^{4}$

\section{Statistical Methodology}

The statistical methods used in this study were consistent with a personcentered approach to data analysis that emphasizes individual differences in development (Magnusson, 1998). We used GGMM (B. Muthén \& Muthén, 2000) and the Mplus Version 2 statistical software package (L. K. Muthén \& Muthén, 1998) to identify distinct patterns of growth in aggression over time. Like traditional growth modeling techniques, GGMM estimates latent variables based on multiple indicators. The multiple indicators of latent growth parameters correspond to repeated univariate outcomes at different time points. However, rather than assuming that the population is constructed of a single continuous distribution, GGMM tests whether the population is constructed of two or more discrete classes (pathways) of individuals, with the goal of determining optimal class membership for each individual. Evidence for these different pathways in aggressive behavior development exists when models involving two or more latent classes of growth provide a better fit than a traditional growth model.

GGMM is similar to the semi-parametric group-based (SPGB) modeling approach (PROC TRAJ in SAS) described by Nagin (1999) in that classes define different trends over time in repeated measures (B. Muthén, 2000). However, unlike SPGB, GGMM allows for the modeling of class-specific levels of variation. For models in which all parameters are the same, GGMM and SPGB provide identical results. GGMM was selected to allow for the possibility of heterogeneity within classes because it did not seem reasonable to assume that all youths within a given class would have identical patterns of aggressive behavior. Allowing for heterogeneity also tends to improve overall model fit and classification accuracy (B. Muthén, 2000). The observed time-variant indicators consisted of teacher-rated classroom aggression measured at nine time points: the fall and spring semesters of first grade, the fall and spring semesters of second grade, and the spring semesters of third through seventh grades.

\section{Missing Data}

The estimates of parameters in the models were adjusted for attrition. All longitudinal studies experience attrition when following participants over time (Hanson, Tobler, \& Graham, 1990). The Mplus software program used a full-information maximum-likelihood estimation under the assumption that the data were missing at random (MAR). MAR assumes that the reason for the missing data is either random (i.e., not related to the outcome of interest) or random after incorporating other variables measured in the study (Arbuckle, 1996; Little, 1995). Full-information maximumlikelihood estimation, used in the present study, is widely accepted as an appropriate way of handling missing data (B. Muthén \& Shedden, 1999; Schafer \& Graham, 2002).

Overall, the percentages of boys in the sample who were missing data at given time points were as follows: missing $0-1$ time points, $40.1 \%$; 2-3 time points, $25.9 \%$; 4-5 time points, $17.6 \%$; and $6-8$ time points, $16.5 \%$. The Mplus software bases its estimates on all available time points for a given case. To assess the extent of missing data in the dataset, the Mplus software provides a covariance "coverage" matrix that gives the proportion of available observations for each indicator variable and pairs of variables, respectively. The minimum coverage necessary for models to converge is .10 (L. K. Muthén \& Muthén, 1998). In the present study, coverage ranged from .40 to .91 , more than adequate for acceptable estimation.

\section{Results}

\section{Descriptive Statistics}

Observed means of aggressive behavior across the seven time points are provided in Table 1 and depicted in Figure 1. On average, boys in the present sample exhibited low levels of aggression throughout the course of elementary and early middle school. Correlations between aggression ratings across the nine time points are provided in Table 2 .

Frequencies for outcome variables for the whole sample were as follows: CD diagnosis, 19.2\%; ASPD diagnosis, $15.5 \%$; juvenile court involvement, $35.4 \%$; adult court involvement, $24.6 \%$. In order to determine the extent to which baseline (fall semester of first grade) aggression ratings predicted these later antisocial outcomes, we divided participants into quartiles on the basis of their baseline aggression scores. Logistic regressions were conducted to see the extent to which the aggression quartile scores predicted antisocial outcomes. As shown in Table 3, boys who fell in the third and fourth quartiles were at 2-3 times greater risk for having a CD diagnosis, an ASPD diagnosis, or a juvenile or adult arrest.

\footnotetext{
${ }^{4}$ Similar confounds between race and poverty were obtained in our preliminary model testing. For example, when race was examined independent of free lunch status, African Americans were more likely than Caucasian youths to be assigned to the increasing aggression trajectory, but when both race and free lunch status were included in the models, African American youths were equally or less likely than Caucasian youths to be assigned to a high-risk trajectory. Chi-square difference testing between various models revealed that the best-fitting growth model was the one that excluded ethnicity.
} 


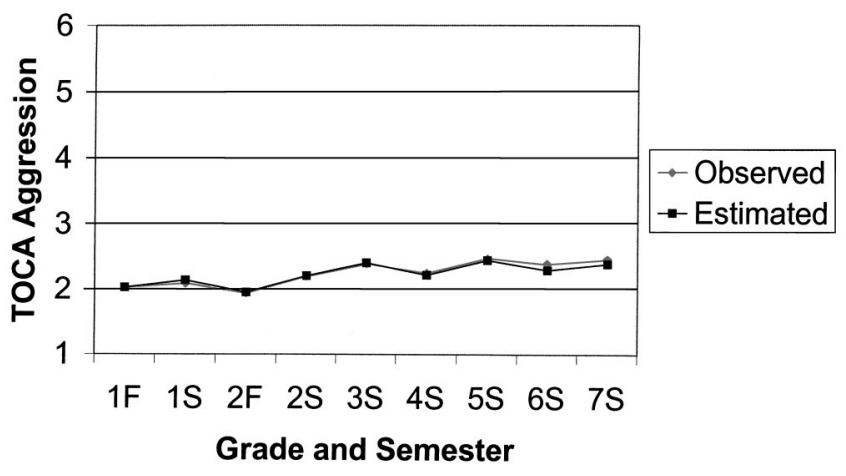

Figure 1. Observed and estimated means on Teacher Observation of Classroom Adaptation (TOCA) Aggression with latent quadratic growth factor. $\mathrm{F}=$ fall semester; $\mathrm{S}=$ spring semester.

\section{Growth Models and Trajectory Classes}

Characteristics of the overall pattern of growth in aggressive behavior were estimated using growth modeling. Intercept-only (i.e., no growth in aggression over time), intercept + linear, and intercept + linear + quadratic (i.e., nonlinear) growth functions were all fitted to the data to determine which function best fit the underlying growth process for the whole sample. Because these models are nested, chi-square difference tests were used to determine whether differences in fit between models were significant. As shown in Table 4, chi-square difference testing revealed that the intercept + linear + quadratic growth function provided the best fit to the data, and it was selected as the base model from which latent classes of growth were identified.

Several parameters were then added to the one-class growth model to improve model fit. First, residual variances of aggressive behavior between the fall and spring semesters of the first and second grades were allowed to co-vary to account for the fact that the same teacher rated each participant's aggression twice within the same school year. Second, because the variance of the quadratic growth factor and the covariance between the intercept and slope factors were very small and not statistically significant when freely estimated, these parameters were set to zero. These parameters were selected on the basis of modification indices and their respective expected parameter change (Saris, Satorra, \& Soerbom, 1987; Soerbom, 1989). Observed and estimated means at each time point for the modified overall growth model are provided in Figure 1.

Following B. Muthén et al. (2002), we obtained fit indices for 1-6 classes. Because models with different numbers of latent classes are not nested, a range of fit indices was used for model comparison: the Bayesian information criterion (BIC; G. Schwartz, 1978); the sample-size adjusted Bayesian information criterion (SSABIC; Sclove, 1987); and the Akaike information criterion (AIC; Akaike, 1987). For each of these, lower scores represent better-fitting models. Entropy refers to the average classification accuracy in the assignment of participants to classes; higher scores are better. As shown in Table 5, by all criteria, model fit improved with the inclusion of more latent classes of growth up to four classes; however, there was a discrepancy between the fit indices regarding the addition of more classes. Although the BIC suggested that the four-class solution was optimal, the SSABIC and the AIC suggested that a five-class solution was best. For the sake of parsimony and consistency among all the fit indices, we selected the four-class solution as the best-fitting model. The four-class model was modified to improve fit further by allowing for differences in residual variances between classes and by setting growth parameters to zero for the normative (nonaggressive) class; these modifications resulted in better fit relative to the unmodified model $(\mathrm{BIC}=4,505.97, \mathrm{SSABIC}=4,388.63$, $\mathrm{AIC}=4,369.30)$.

Of substantive interest was whether concentration problems and peer rejection measured in first grade predicted trajectory class membership after the effects of free lunch status were controlled. Accordingly, class membership was regressed on these three covariates. Chi-square difference testing revealed that the inclusion of covariates in the prediction of class membership improved model fit (see Table 6). Although the association between covariates and model growth parameters was not of substantive interest in the present study, two additional models that included these associations were considered in the interest of finding an optimal model solution. As shown in Table 6, the model that regressed growth parameters for the overall model onto covariates had significantly better fit, but the model that allowed these regressions to vary between classes did not. Thus, the final model included the regression paths of overall growth parameters on covariates $(\mathrm{BIC}=4,490.87$, SSABIC $=4,316.45$, $\mathrm{AIC}=4,287.72)$.

A graphical depiction of the resulting four-class solution is presented in Figure 2. The model identifies four distinct trajectories of aggressive behavior: a chronic high aggression trajectory,

Table 2

Correlations of Teacher Ratings of Boys' Aggression From First to Seventh Grades

\begin{tabular}{|c|c|c|c|c|c|c|c|c|c|}
\hline Semester and grade & $\begin{array}{c}\text { Fall, } \\
\text { Grade } 1\end{array}$ & $\begin{array}{l}\text { Spring, } \\
\text { Grade } 1\end{array}$ & $\begin{array}{c}\text { Fall, } \\
\text { Grade } 2\end{array}$ & $\begin{array}{l}\text { Spring, } \\
\text { Grade } 2\end{array}$ & $\begin{array}{l}\text { Spring, } \\
\text { Grade } 3\end{array}$ & $\begin{array}{l}\text { Spring, } \\
\text { Grade } 4\end{array}$ & $\begin{array}{l}\text { Spring, } \\
\text { Grade } 5\end{array}$ & $\begin{array}{l}\text { Spring, } \\
\text { Grade } 6\end{array}$ & $\begin{array}{l}\text { Spring, } \\
\text { Grade } 7\end{array}$ \\
\hline Fall, Grade 1 & - & & & & & & & & \\
\hline Spring, Grade 1 & 0.786 & - & & & & & & & \\
\hline Fall, Grade 2 & 0.558 & 0.547 & - & & & & & & \\
\hline Spring, Grade 2 & 0.494 & 0.462 & 0.769 & - & & & & & \\
\hline Spring, Grade 3 & 0.456 & 0.471 & 0.566 & 0.571 & - & & & & \\
\hline Spring, Grade 4 & 0.424 & 0.439 & 0.463 & 0.495 & 0.468 & - & & & \\
\hline Spring, Grade 5 & 0.413 & 0.446 & 0.521 & 0.504 & 0.529 & 0.637 & - & & \\
\hline Spring, Grade 6 & 0.374 & 0.362 & 0.543 & 0.513 & 0.542 & 0.515 & 0.562 & - & \\
\hline Spring, Grade 7 & 0.206 & 0.323 & 0.298 & 0.318 & 0.462 & 0.455 & 0.564 & 0.490 & - \\
\hline
\end{tabular}

Note. All correlations are significant at the $p<.01$ level. 
Table 3

Baseline Aggression and Distal Antisocial Outcomes

\begin{tabular}{|c|c|c|c|c|c|c|c|c|}
\hline \multirow{2}{*}{$\begin{array}{c}\text { Fall, Grade } 1 \\
\text { Aggression percentile }\end{array}$} & \multicolumn{2}{|c|}{ Conduct disorder } & \multicolumn{2}{|c|}{$\begin{array}{c}\text { Antisocial } \\
\text { personality disorder }\end{array}$} & \multicolumn{2}{|c|}{ Juvenile arrest } & \multicolumn{2}{|c|}{ Adult arrest } \\
\hline & OR & $95 \% \mathrm{CI}$ & OR & $95 \% \mathrm{CI}$ & OR & $95 \% \mathrm{CI}$ & OR & $95 \% \mathrm{CI}$ \\
\hline 26th-50th & 0.82 & $0.30-2.22$ & 0.55 & $0.17-1.80$ & 1.06 & $0.52-2.17$ & 1.80 & $0.77-4.20$ \\
\hline $51 \mathrm{st}-75$ th & $2.91 *$ & $1.21-7.02$ & $2.76^{*}$ & $1.07-7.11$ & $2.74 *$ & $1.36-5.50$ & $3.61^{*}$ & $1.59-8.22$ \\
\hline 76th-100th & 2.12 & $0.84-5.38$ & 2.51 & $0.94-6.72$ & $2.13^{*}$ & $1.04-4.36$ & $2.40 *$ & $1.02-5.66$ \\
\hline
\end{tabular}

Note. All odds ratios (ORs) are relative to boys in the lowest quartile (i.e., 25th percentile or lower). $\mathrm{CI}=$ confidence interval.

$* p<.05$.

consisting of those boys ( $n=26$, or $9 \%$ of the sample) whose aggression started high in first grade, remained high throughout elementary school, and declined slightly by seventh grade; a moderate aggression trajectory, consisting of boys ( $n=155$, or 52\%) whose aggression remained at a moderate level with a slight increase from first grade through seventh grade; an increasing aggression trajectory, consisting of boys $(n=22$, or $7 \%)$ whose first-grade aggression was low but who became increasingly more aggressive through seventh grade; and a low aggression trajectory, consisting of boys ( $n=94$, or $32 \%)$ with consistently low levels of aggression over time. Contrary to our hypotheses, we did not find a trajectory of desisting aggression. Table 7 lists parameter estimates for the final four-class model.

\section{Risk Factors Associated With Aggression Trajectories}

The first-grade risk factors selected for this study were included in model building as a means of improving model fit and the accuracy of assignments of individuals to trajectory classes. However, the extent to which risk factors differed between aggression trajectories was also of substantive interest. We hypothesized that attention and concentration problems and peer rejection would be highest among boys in the chronic high aggression trajectory. We also expected these variables to differentiate boys in the increasing trajectory from those in the nonaggressive trajectory. To test these hypotheses, we compared odds ratios between each class using the nonaggressive class as the reference group.

The association between risk factors and aggression trajectory classes is outlined in Table 8. Boys with chronic high, moderate, and increasing aggression trajectories all were at higher risk for concentration problems than were nonaggressive boys (ORs = 1.95-2.38). Boys with a chronic high aggression trajectory were more likely than their nonaggressive counterparts to experience peer rejection $(\mathrm{OR}=2.33)$, but boys with increasing aggression were less likely $(\mathrm{OR}=0.15)$.

\section{Prediction to Distal Outcomes}

The ability of the trajectories to predict antisocial outcomes is one important criterion by which to judge the external validity of the aggression classifications. To determine whether the identified trajectories predicted later antisocial behavior, we regressed each of the four distal outcomes (i.e., CD and ASPD diagnoses and juvenile and adult court involvement) on the latent class membership variables. Because the distal outcomes were highly collinear, each outcome was tested in a separate model. The prevalence of the occurrence of the distal outcome within each class (based on threshold estimates) is shown in Table 9. For a better understanding of the likelihood of having a particular antisocial outcome given membership in a trajectory class, ORs are presented. For each OR, the reference condition was membership in the nonaggressive class.

As shown in Table 9, membership in the chronic high and increasing aggression trajectory classes was associated with significantly increased risk for juvenile and adult arrest, CD diagnosis, and ASPD diagnosis (ORs ranged from 8.64 to 26.58). Boys with a pattern of moderate aggression were at significantly increased risk for juvenile and adult adjudication but not for CD or ASPD. It should be noted that a portion of boys with a nonaggressive trajectory pattern $(9 \%-16 \%)$ did go on to have antisocial outcomes in later adolescence and young adulthood.

\section{Discussion}

A primary goal of the present study was to provide empirical support for current conceptualizations (Loeber \& Stouthamer-

Table 4

Growth Functions of Overall (Single-Class) Growth Model

\begin{tabular}{|c|c|c|c|c|c|c|}
\hline \multirow[b]{2}{*}{ Type of model } & \multicolumn{3}{|c|}{ Model fit } & \multicolumn{3}{|c|}{ Likelihood ratio test } \\
\hline & $\chi^{2}$ & $d f$ & $p<$ & Model comparison & Difference $\chi^{2}$ & $d f$ \\
\hline 1. Intercept only & 146.52 & 41 & .0000 & & & \\
\hline 2. Intercept + linear & 83.45 & 38 & .0000 & 2 vs. 1 & $63.12 * *$ & 3 \\
\hline 3. Intercept + linear + quadratic & 65.55 & 34 & .0000 & 3 vs. 2 & $17.90 *$ & 4 \\
\hline
\end{tabular}

$* p<.05$. ** $p<.01$. 
Table 5

Fit Indices for Latent Class Solutions

\begin{tabular}{lcccc}
\hline Number of latent classes & BIC & SSABIC & AIC & Entropy \\
\hline 1 class (growth model) & $4,803.57$ & $4,752.82$ & $4,744.47$ & \\
2 classes & $4,761.72$ & $4,698.30$ & $4,687.85$ & .862 \\
3 classes & $4,744.05$ & $4,667.94$ & $4,655.40$ & .826 \\
4 classes & $4,732.27$ & $4,643.47$ & $4,628.85$ & .822 \\
5 classes & $4,733.89$ & $4,629.24$ & $4,612.00$ & .816 \\
6 classes & $4,747.22$ & $4,633.05$ & $4,614.24$ & .782 \\
\hline
\end{tabular}

Note. For all fit indices, smaller numbers represent better fit. Entropy refers to the average classification accuracy in assigning participants to classes. BIC $=$ Bayesian information criterion; SSABIC $=$ sample-size adjusted Bayesian information criterion; AIC $=$ Akaike information criterion.

Loeber, 1998; Moffitt, 1993; Patterson et al., 1989) of the developmental pathways to antisocial behavior in adolescence and adulthood. To that end, we sought to identify distinct subgroups of youths with different trajectories of aggressive behavior over the course of elementary and middle school. We then examined the utility of these trajectory classifications in predicting distal antisocial outcomes in adolescence and adulthood and sought to identify risk behaviors at the entrance to elementary school that would help to differentiate the pathways from one another. To accomplish our aims, we selected an epidemiologically defined population of urban, primarily African American youths, thus providing a muchneeded focus on antisocial behavior development within understudied minority communities (U.S. Public Health Service, 2001). Moreover, the newest generation of growth modeling techniques, GGMM, was used for its advantages over other types of latent growth models, advantages that included more accurate assignments to trajectory classes (by allowing within-class variation) and unbiased estimates of the associations of risk factors and distal outcomes with trajectory classes (by adjusting these estimates for the uncertainty of class memberships).

\section{Aggression Trajectories and Antisocial Outcomes}

Four distinct trajectories of aggressive behavior were identified and validated through their ability to predict distal (late adolescent and adult) antisocial outcomes. Several of these trajectories were similar to those found in other growth modeling studies of aggressive behavior and with theoretical models. A substantial portion of boys in the present study (32\%) exhibited low levels of aggression throughout development and had low rates of later antisocial outcomes, a finding consistent with our hypotheses and with the results of Broidy et al. (2003), Maughan et al. (2000), and Nagin and Tremblay (1999). Also similar to results from previous studies and results with theoretical models was our identification of a group of boys (chronic high aggression, 9\%) who displayed consistently high levels of aggression and were at great risk for later antisocial outcomes. To our knowledge, the present study is the first to empirically identify a group of boys (increasing aggression, $7 \%$ ) with an aggression trajectory that started low but increased throughout elementary and middle school.

The chronic high and increasing aggression trajectories identified in this study correspond closely to Loeber and StouthamerLoeber's (1998) proposed categories of life-course-persistent offenders. Given that the chronic high aggression group in the present study already had high levels of aggressive behavior upon school entry, it appears to correspond to Loeber and StouthamerLoeber's life-course-persistent, preschool-onset type. Loeber and Stouthamer-Loeber's second life-course-persistent group, the child-onset type, was supported empirically for the first time (to our knowledge) in the present study with the identification of the increasing aggression group. Boys with an increasing aggression trajectory were indistinguishable from nonaggressive boys until late in first grade, when their aggressive behavior began to increase and continued to do so through seventh grade. As predicted in the Loeber and Stouthamer-Loeber model, both of these life-course-

Table 6

Comparison of Four-Class Models With Covariates

\begin{tabular}{|c|c|c|c|c|c|}
\hline \multirow[b]{2}{*}{ Type of model } & \multicolumn{2}{|c|}{ Model fit } & \multicolumn{3}{|c|}{ Likelihood ratio test } \\
\hline & $\begin{array}{l}\log \\
\text { likelihood }\end{array}$ & $\begin{array}{c}\text { No. of free } \\
\text { parameters (fp) }\end{array}$ & $\begin{array}{l}\text { Model } \\
\text { comparison }\end{array}$ & $\Delta \chi^{2}$ & $\Delta \mathrm{fp}$ \\
\hline 1. No covariates & $-2,146.54$ & 37 & & & \\
\hline $\begin{array}{l}\text { 2. Regressions of class membership on } \\
\text { covariates }\end{array}$ & $-2,101.75$ & 46 & 1 vs. 2 & $91.80^{* *}$ & 9 \\
\hline $\begin{array}{l}\text { 3. Model } 2+\text { regressions of overall } \\
\text { growth parameters on covariates }\end{array}$ & $-2,088.86$ & 55 & 2 vs. 3 & $25.78^{*}$ & 9 \\
\hline $\begin{array}{l}\text { 4. Model } 3+\text { regressions of class-specific } \\
\text { growth parameters on covariates }\end{array}$ & $-2,077.24$ & 82 & 3 vs. 4 & 23.24 & 27 \\
\hline
\end{tabular}

Note. Chi-square difference testing was based on the likelihood-ratio chi-square test.

$* p<.05$. ** $p<.01$. 


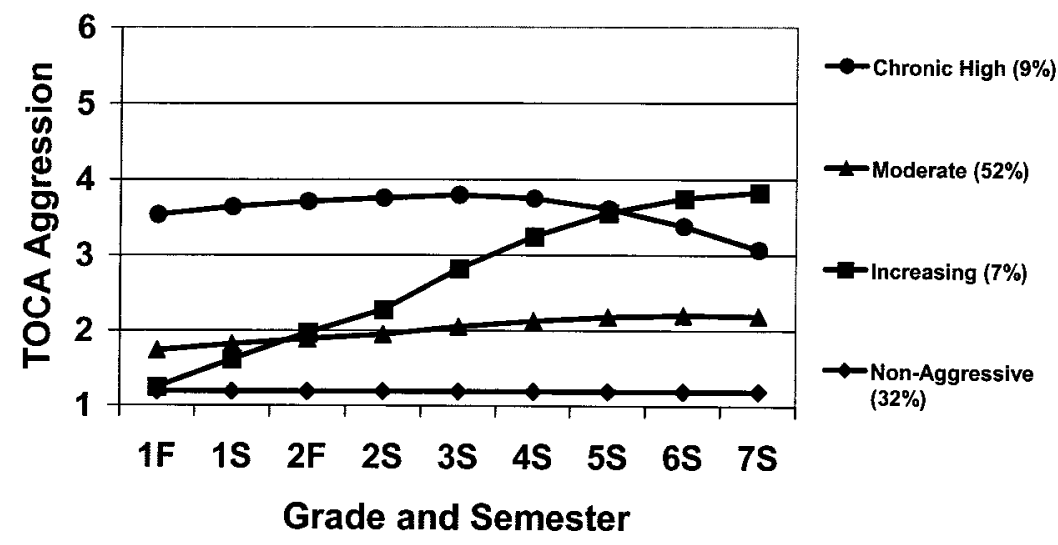

Figure 2. Model-estimated means for the four-class general growth mixture solution. TOCA $=$ Teacher Observation of Classroom Adaptation; $\mathrm{F}=$ fall semester; $\mathrm{S}=$ spring semester.

Table 7

Parameter Estimates for Four-Class Model With Covariates

\begin{tabular}{|c|c|c|c|c|c|c|c|c|}
\hline \multirow[b]{3}{*}{ Parameter } & \multicolumn{8}{|c|}{ Aggression growth estimates } \\
\hline & \multicolumn{2}{|c|}{ Chronic high } & \multicolumn{2}{|c|}{ Moderate } & \multicolumn{2}{|c|}{ Increasing } & \multicolumn{2}{|c|}{ Nonaggressive } \\
\hline & Estimate & $S E$ & Estimate & $S E$ & Estimate & $S E$ & Estimate & $S E$ \\
\hline$\alpha_{0}$ & 3.540 & 0.275 & 1.739 & 0.146 & 1.249 & 0.148 & 1.192 & 0.057 \\
\hline$\alpha_{1}$ & 0.213 & 0.175 & 0.161 & 0.074 & 0.774 & 0.158 & 0.000 & Fixed \\
\hline$\alpha_{2}$ & -0.044 & 0.027 & -0.014 & 0.011 & -0.058 & 0.022 & 0.000 & Fixed \\
\hline $\mathrm{V}\left(\zeta_{0}\right)$ & 0.081 & 0.025 & 0.081 & 0.025 & 0.157 & 0.045 & 0.023 & 0.018 \\
\hline $\mathrm{V}\left(\zeta_{1}\right)$ & 0.000 & 0.001 & 0.000 & 0.001 & 0.000 & 0.001 & 0.000 & 0.001 \\
\hline $\mathrm{V}\left(\zeta_{2}\right)$ & 0.000 & Fixed & 0.000 & Fixed & 0.000 & Fixed & 0.000 & Fixed \\
\hline$\gamma_{0 \mid \text { Concentration }}$ & 0.119 & 0.035 & 0.119 & 0.035 & 0.119 & 0.035 & 0.119 & 0.035 \\
\hline$\gamma_{0 \mid \text { Peer Rejection }}$ & -0.027 & 0.060 & -0.027 & 0.060 & -0.027 & 0.060 & -0.027 & 0.060 \\
\hline$\gamma_{0 \mid \text { Lunch Status }}$ & -0.030 & 0.085 & -0.030 & 0.085 & -0.030 & 0.085 & -0.030 & 0.085 \\
\hline$\gamma_{1 \mid \text { Concentration }}$ & -0.011 & 0.021 & -0.011 & 0.021 & -0.011 & 0.021 & -0.011 & 0.021 \\
\hline$\gamma_{1 \mid \text { Peer Rejection }}$ & -0.020 & 0.029 & -0.020 & 0.029 & -0.020 & 0.029 & -0.020 & 0.029 \\
\hline$\gamma_{1 \mid \text { Lunch Status }}$ & 0.015 & 0.058 & 0.015 & 0.058 & 0.015 & 0.058 & 0.015 & 0.058 \\
\hline$\gamma_{2 \mid \text { Concentration }}$ & -0.001 & 0.003 & -0.001 & 0.003 & -0.001 & 0.003 & -0.001 & 0.003 \\
\hline$\gamma_{2 \mid \text { Peer Rejection }}$ & 0.004 & 0.005 & 0.004 & 0.005 & 0.004 & 0.005 & 0.004 & 0.005 \\
\hline$\gamma_{2 \mid \text { Lunch Status }}$ & 0.002 & 0.009 & 0.002 & 0.009 & 0.002 & 0.009 & 0.002 & 0.009 \\
\hline $\begin{array}{l}\gamma_{2 \mid \text { Lunch Status }} \\
\mathrm{V}\left(\varepsilon_{1 \mathrm{~F}}\right)\end{array}$ & 0.520 & 0.070 & 0.520 & 0.070 & 0.520 & 0.070 & 0.217 & 0.051 \\
\hline $\mathrm{V}\left(\varepsilon_{1 \mathrm{~S}}\right)$ & 0.485 & 0.070 & 0.485 & 0.070 & 0.485 & 0.070 & 0.214 & 0.049 \\
\hline $\mathrm{V}\left(\varepsilon_{2 \mathrm{~S}}\right)$ & 0.523 & 0.080 & 0.523 & 0.080 & 0.523 & 0.080 & 0.238 & 0.040 \\
\hline $\mathrm{V}\left(\varepsilon_{2 \mathrm{~F}}\right)$ & 0.642 & 0.100 & 0.642 & 0.100 & 0.642 & 0.100 & 0.289 & 0.057 \\
\hline $\mathrm{V}\left(\varepsilon_{3 \mathrm{~S}}\right)$ & 1.083 & 0.157 & 1.083 & 0.157 & 1.083 & 0.157 & 0.134 & 0.139 \\
\hline $\mathrm{V}\left(\varepsilon_{4 \mathrm{~S}}\right)$ & 0.714 & 0.094 & 0.714 & 0.094 & 0.714 & 0.094 & 0.043 & 0.009 \\
\hline $\mathrm{V}\left(\varepsilon_{5 \mathrm{~s}}\right)$ & 0.663 & 0.080 & 0.663 & 0.080 & 0.663 & 0.080 & 0.133 & 0.060 \\
\hline $\mathrm{V}\left(\varepsilon_{6 \mathrm{~S}}\right)$ & 0.730 & 0.099 & 0.730 & 0.099 & 0.730 & 0.099 & 0.101 & 0.031 \\
\hline $\mathrm{V}\left(\varepsilon_{7 \mathrm{~S}}\right)$ & 0.703 & 0.107 & 0.703 & 0.107 & 0.703 & 0.107 & 0.128 & 0.041 \\
\hline $\mathrm{C}\left(\varepsilon_{1 \mathrm{~F}}, \varepsilon_{1 \mathrm{~S}}\right)$ & 0.175 & 0.046 & 0.175 & 0.046 & 0.175 & 0.046 & 0.175 & 0.046 \\
\hline $\mathrm{C}\left(\varepsilon_{2 \mathrm{~F}}, \varepsilon_{2 \mathrm{~S}}\right)$ & 0.170 & 0.048 & 0.170 & 0.048 & 0.170 & 0.048 & 0.170 & 0.048 \\
\hline $\mathrm{C}\left(\alpha_{0}, \alpha_{1}\right)$ & 0.000 & Fixed & 0.000 & Fixed & 0.000 & Fixed & 0.000 & Fixed \\
\hline $\mathrm{C}\left(\alpha_{0}, \alpha_{2}\right)$ & 0.000 & Fixed & 0.000 & Fixed & 0.000 & Fixed & 0.000 & Fixed \\
\hline $\mathrm{C}\left(\alpha_{1}, \alpha_{2}\right)$ & 0.000 & Fixed & 0.000 & Fixed & 0.000 & Fixed & 0.000 & Fixed \\
\hline$\alpha \mathrm{c}$ & -6.141 & 0.950 & -1.738 & 0.529 & -1.134 & 0.758 & - & - \\
\hline
\end{tabular}

Note. Estimates of covariates on latent class membership are depicted in Table 8. Dashes indicate that cells are empty because the nonaggressive class was the reference group to which the other classes were compared.

Model: $\mathrm{y}_{i t}=\eta_{0 i}+\eta_{1 i} \mathrm{a}_{t}+\eta_{2 i} \mathrm{a}_{t}^{2}+\varepsilon_{i t} \mathrm{a}_{t}=0,0.5,1.0,1.5,2.5,3.5,4.5,5.5,6.5 . \eta_{0 i}=\alpha_{0 k}+\gamma_{0 k} \mathrm{C}_{i}+\zeta_{0 i} ; \eta_{1 i}=\alpha_{1 k}+\gamma_{1 k} \mathrm{C}_{i}+\zeta_{1 i} ; \eta_{2 i}=\alpha_{2 k}+\gamma_{2 k} \mathrm{C}_{i}$ $+\zeta_{2 i} . \mathrm{C}_{i}=$ concentration problems, peer rejection, lunch status. $\mathrm{V}(\zeta \mid$ class $k)=\psi_{k}$. V $(\varepsilon \mid$ class $k)=\Theta_{k}$. 
Table 8

The Association Between Trajectory Class Membership and Covariates

\begin{tabular}{clll}
\hline \multicolumn{1}{c}{ Covariate } & Trajectory class & OR & 95\% CI \\
\hline Concentration problems & Chronic high & $2.38^{*}$ & $1.54-3.65$ \\
& Moderate & $2.00^{*}$ & $1.46-2.74$ \\
& Increasing & $1.95^{*}$ & $1.23-3.11$ \\
Peer rejection & Nonaggressive & 1.00 & \\
& Chronic high & $2.33^{*}$ & $1.13-4.82$ \\
& Moderate & 1.02 & $0.58-1.80$ \\
Eligible for free lunch & Increasing & $0.15^{*}$ & $0.03-0.73$ \\
& Nonaggressive & 1.00 & \\
& Chronic high & $3.96^{*}$ & $1.25-12.59$ \\
& Moderate & $2.41^{*}$ & $1.08-4.69$ \\
& Increasing & $3.63^{*}$ & $1.07-12.37$ \\
\hline
\end{tabular}

Note. $\quad \mathrm{OR}=$ odds ratio $\mathrm{CI}=$ confidence interval. $* p<.05$.

persistent groups went on to show high rates of antisocial behavior in young adulthood.

The majority of boys (52\%) fell into the fourth trajectory identified in this study, the moderate aggression trajectory. Although other modeling studies have found trajectories for boys with moderate levels of aggression during elementary school, in most cases, moderate trajectories were associated with later declines in aggression and no increased risk for antisocial outcomes (e.g., Broidy et al., 2003; Maughan et al., 2000; Nagin \& Tremblay, 1999). In the present study, boys with moderate aggression showed a slight increase in aggression over time and were at increased risk relative to nonaggressive boys for at least some antisocial outcomes (i.e., juvenile and adult adjudication). Their level of aggressive behavior problems in elementary and middle school was between those of the chronic high aggression and low aggression classes. Although they were not at increased risk for CD or ASPD, their odds ratios were in the predicted direction for all antisocial outcomes. Thus, boys with moderate aggression fall between the chronic high and nonaggressive groups in terms of level of aggression and level of long-term risk. Although more research is needed to understand the factors that explain the course and prognosis of this group, it seems reasonable to recommend that these boys also be a focus of preventive efforts.

There was no evidence in the present study for a high-butdesisting aggression group, which had been hypothesized and had been found in previous modeling studies with high-risk samples (e.g., Broidy et al., 2003; Maughan et al., 2000; Nagin \& Tremblay, 1999). Although boys with a pattern of chronic high aggression did show some decreases in aggressive behavior starting at around fifth grade, this decline occurred after several years of high or increasing aggression, a pattern more consistent with chronic high aggression. However, it should be noted that a sizeable portion of boys with chronic high aggression (between 26\%-52\%, depending on the outcome examined) did not go on to have a

Table 9

Antisocial Outcomes by Class Membership

\begin{tabular}{|c|c|c|c|c|}
\hline Outcome & Trajectory class & $\begin{array}{c}\text { Percentage } \\
\text { with outcome }\end{array}$ & OR & $95 \%$ CI \\
\hline \multirow[t]{4}{*}{ Juvenile arrest } & Chronic high & 73 & $20.33^{*}$ & $1.81-228.15$ \\
\hline & Moderate & 42 & $5.50 *$ & $1.81-16.68$ \\
\hline & Increasing & 72 & $19.32 *$ & $1.72-217.02$ \\
\hline & Nonaggressive & 12 & & \\
\hline \multirow[t]{4}{*}{ Adult arrest } & Chronic high & 48 & $9.26^{*}$ & $1.91-48.91$ \\
\hline & Moderate & 26 & $3.71 *$ & $1.62-8.50$ \\
\hline & Increasing & 46 & $8.64 *$ & $3.53-21.12$ \\
\hline & Nonaggressive & 9 & & \\
\hline \multirow[t]{4}{*}{ Conduct disorder } & Chronic high & 74 & $15.36^{*}$ & $2.03-116.75$ \\
\hline & Moderate & 20 & 1.37 & $0.44-4.26$ \\
\hline & Increasing & 69 & $11.98^{*}$ & $1.55-91.84$ \\
\hline & Nonaggressive & 16 & & \\
\hline \multirow{4}{*}{ Antisocial personality disorder } & Chronic high & 71 & $26.58^{*}$ & $11.82-59.74$ \\
\hline & Moderate & 16 & 1.98 & $0.59-6.55$ \\
\hline & Increasing & 62 & $17.29 *$ & $1.62-184.93$ \\
\hline & Nonaggressive & 9 & & \\
\hline
\end{tabular}

Note. $\quad \mathrm{OR}=$ odds ratio; $\mathrm{CI}=$ confidence interval.

${ }^{\mathrm{a}}$ Percentages are based on threshold estimates.

$* p<.05$. 
particular antisocial outcome and might be considered to be desisters from early, chronic aggressive behavior problems. There are at least two possible explanations for why the present study failed to empirically identify this group. First, the relatively small sample size in this study as well as the low prevalence of boys with a chronic high aggression pattern $(9 \%)$ in this community sample may have resulted in a subsample size too small for further empirical subdivision (i.e., not enough meaningful variation within this class to justify the extraction of an additional group). Second, it is possible that the probability of desisting from aggression may be much smaller in urban areas characterized by high rates of antisocial behavior and violence. To extend Patterson et al.'s (1992) coercion model of the development of antisocial behavior from the family to school and neighborhood contexts, perhaps coercive children may "train" teachers, classmates, and peers to be coercive. In turn, the increased prevalence of coercive exchanges within schools and neighborhoods may serve to maintain in cyclic fashion antisocial behavior and violence at the individual and community level.

As in other modeling studies (e.g., Broidy et al., 2003), we were also unable to identify another hypothesized group, the "late starters" or "adolescent onset offenders," as traditionally defined by Patterson (1996) and Moffitt (1993), that is, those youths who first display aggressive behavior in early adolescence. We did find an increasing aggression class and suggested that the same etiologic processes elaborated by Patterson et al. (1992) for late starters might also be at work for this increasing class but might occur earlier in development. Alternatively, the sample may have been too young for late starters to be identified given that the final assessment point in our growth model was when the boys were in seventh grade (i.e., at approximately age 12). It is important to note that within the low aggression class, a portion of the boys (9\%$16 \%$ ) did go on to have an antisocial outcome. Potentially, these boys may be the late starters hypothesized by Patterson et al. and Moffitt.

\section{Risk Factors and Risk Trajectories}

The ability of risk factors to differentiate boys on various trajectories also was explored in the present study. We found support for the hypothesis that the increasing aggression class would have a higher level of concentration problems than the low aggression class at entrance to first grade. Thus, teacher ratings of youths' concentration problems at school entry, which can be obtained at the population level in both a time- and cost-efficient manner, may be an important tool for more precisely targeting our limited resources for preventive interventions. Of course, further replication of these results will be necessary before a firm recommendation can be made with respect to using teacher-rated concentration problems to identify early in development youths in need of preventive interventions. Drawing on the work of Patterson et al. (1992), we offered in the introduction a potential explanation for the role of concentration problems in discriminating the low aggression class from the increasing aggression class. However, further research is needed to explicate this proposed mechanism.

Contrary to our hypothesis, peer rejection did not prove to be higher among the increasing aggression class than among the low aggression class. One possible explanation for this finding is measurement error given that we were relying on teachers to assess peer rejection and only used a single item to do so. However, peer rejection did prove to be higher in the chronic high aggression class than in the low aggression class. Thus, we are hesitant to attribute the finding to weak measurement. It is worth noting that Coie, Terry, Lenox, and Lochman (1995) and Bagwell, Coie, Terry, and Lochman (2000) reported that aggression is more strongly related to deviant peer associations than to peer rejection. Moreover, in their research, nonrejected aggressive youths were more likely to be affiliated with deviant peers than were rejected aggressive youths. Thus, owing to their lower levels of peer rejection relative to the low aggression class, the increasing aggression class in our study may have been at higher risk for deviant peer associations, which in turn, increased the risk for antisocial behavior in adolescence and young adulthood. Alternatively, it is possible that boys with an increasing aggression trajectory experience higher rates of peer rejection over time as their aggression increases.

As expected and in support of Loeber and Stouthamer-Loeber's (1998) model, attention and/or concentration problems in first grade were associated with the chronic high aggression trajectory (i.e., the life-course-persistent, preschool-onset type). This finding is consistent with the idea that the aggression exhibited by boys with a chronic high trajectory may be linked to neuropsychological deficits that are also associated with ADHD (Jensen et al., 1997; Moffitt, 1993). As noted, peer rejection was also found to be positively associated with the chronic high aggression trajectory. As expected, boys with chronic high aggression already were facing higher levels of peer rejection by their classmates as early as the fall semester of first grade.

\section{Implications for Prevention}

These analyses illustrate the need to assess youths across the course of development in order to reliably predict later outcomes. As shown in Table 1, using only baseline aggression to screen these youths for potential problems in antisocial behavior would have resulted in fairly weak prediction. Moreover, by using only the first assessment points, a portion of the youths (the $7 \%$ of the sample on the increasing trajectory) with initially low levels of aggression would have been misidentified as nonaggressive, when in fact they were on a trajectory of increasing aggression. Analyses are currently under way to determine the minimum number of time points necessary for reliable prediction (i.e., a high degree of sensitivity and specificity) of later negative outcomes. Preliminary analyses have shown that at-risk boys can most accurately be predicted when multiple time points are available (Petras et al., 2002).

The potential for these typologies to improve interventions for at-risk youths argues strongly for the use of improved screening and tracking of behavior problems in elementary schools. Schools, as the only public system universally serving youths, are uniquely suited for tracking the developmental course of youths' problematic behaviors and identifying early those youths most at risk. Schools routinely assess students' progress in academic domains, such as achievement, on an annual or semiannual basis. Accordingly, brief, reliable methods for universally tracking youths' behavior problems would not be a radical departure from current practice, especially given that classroom behavior problems are one of the most prevalent and challenging problems facing schools today. Moreover, schools are increasingly called upon to provide 
universal, selected, and even indicated interventions for youths to prevent and address behavior problems. Systematic assessment of student emotional and behavioral problems could provide empirical support for intervention efforts and could help to identify those youths for whom indicated interventions are warranted. By combining data from multiple time points, one could obtain reliable identification of the specific developmental course of a particular youth. By adding a simple self-report instrument—-teacher ratings of aggression, concentration problems, and peer rejection-to the existing evaluation procedures that teachers currently complete on students each year, schools would be in a position to target their school-based mental health services more appropriately and to refer at-risk youth to appropriate services in the community. In addition, annual assessments of classroom behavior could serve as outcome measures for other school-based initiatives such as universal classroom interventions.

Understanding the factors that cause youth aggression to increase, remain stable, or change form over time can lead to the development of preventive interventions that are tailored to meet the needs of youths with different patterns of growth. For example, boys with aggressive behavior that increases over time might benefit from parent training or self-control training programs, whereas boys with a chronic high aggression pattern might require more intensive interventions such as multisystemic therapy (Henggeler, Schoenwald, Borduin, Rowland, \& Cunningham, 1998) or pharmacological treatment. Clinical trials that either randomly assign interventions to aggressive behavior subtypes or that examine the moderating effects of subtype classification on treatment outcomes are needed to improve the tailoring of interventions to the specific needs of youths.

\section{Limitations and Future Research Directions}

There are several limitations of the present study. First, because the study did not examine aggression beyond seventh grade, it is difficult to directly compare the results of this study with those from studies that modeled aggressive behavior with older samples of youths. Second, the time points examined also precluded the identification of a group of boys whose antisocial behavior began later in development (i.e., late starters). Nonetheless, these results provide an important glimpse at the earlier course of aggressive behavior, a vantage point that is critical to the development of early prevention programs. Third, our measure of peer rejection was limited to a single item, which may not have captured subtleties in peer relation characteristics such as peer neglect. Fourth, ratings of aggression, concentration problems, and peer rejection in first grade were based solely on teacher reports, which raises possible concerns about spurious results that are due to method invariance. However, mitigating this concern is the fact that the ratings of aggression made after first grade were made by different teachers. Moreover, measuring both archival and self-report antisocial outcomes at a much later point in development provided strong external validity for the early trajectories and their associated risk factors.

Although the present study involved a predominantly African American sample, we were unable to examine the differential effects of race on growth parameters or class membership because of the confounding of race and poverty in our sample. As noted, African American boys were significantly more likely to be re- ceiving a free school lunch in first grade than were Caucasian boys. The high overlap between these factors limited our ability to include both in our growth mixture models. Forced to choose, we felt that it was more appropriate to include free lunch status as a covariate given the strong association between family income or neighborhood disadvantage and youth antisocial behavior (Attar, Guerra, \& Tolan, 1994; Samaan, 2000). Studies that use sampling techniques designed to address these confounds are needed.

As with all findings regarding youth antisocial behavior development, theories and models need to be expanded to examine risk trajectories for antisocial behavior development among girls. The early course of female antisocial behavior development remains largely unknown. What is known suggests that there are significant gender differences in the course and expression of aggressive behavior over time (Broidy et al., 2003; Eme \& Kavanaugh, 1995; Keenan \& Shaw, 1997). Moreover, it is possible that early aggressive trajectories might place girls at higher risk than boys for other kinds of mental health problems later in life, such as depression or anxiety disorders (Thompson, Wonderlich, Crosby, \& Mitchell, 1999; Tiet, Wasserman, Loeber, McReynolds, \& Miller, 2001).

A final limitation involves the small numbers of boys in several of the trajectory classes. The prevalence rates for life-coursepersistent forms of antisocial behavior are low in community samples, as were the rates of the aggressive trajectories in the present sample. The low prevalence of these developmental patterns resulted in wide confidence intervals in odds ratio testing. This limitation was mitigated somewhat by the inclusion of risk factors and distal outcomes within the growth models themselves to adjust for this uncertainty in the estimates (rather than forcing individuals into their highest probability class). In order to obtain larger numbers of youths in the classes of interest, very large community samples are necessary.

Overall, the findings from this and other modeling studies provide clear evidence for equifinality in youth antisocial behavior. More research is needed to understand the risk factors that precede and exacerbate progression along these different developmental trajectories. For example, indiscriminant parenting and coercive family processes (Patterson, 1982) or parental monitoring (Kilgore, Snyder, \& Lentz, 2000) might be differential risk factors across these trajectories. Studies that explore these possible risk factors in the present sample are currently under way.

\section{References}

Akaike, H. (1987). Factor analysis and AIC. Psychometrika, 52, 317-332. American Psychiatric Association. (1994). Diagnostic and statistical manual of mental disorders (4th ed.). Washington, DC: American Psychiatric Association.

Arbuckle, J. L. (1996). Full information estimation in the presence of incomplete data. In G. A. Marcoulides \& R. E. Schumacker (Eds.), Advanced structural equation modeling: Issues and techniques. Mahwah, NJ: Erlbaum.

Attar, B. K., Guerra, N. G., \& Tolan, P. H. (1994). Neighborhood disadvantage, stressful life events, and adjustment in urban elementary-school children. Journal of Clinical Child Psychology, 23, 391-400.

Bagwell, C. L., Coie, J. D., Terry, R. A., \& Lochman, J. E. (2000). Peer clique participation and social status in preadolescence. Merrill-Palmer Quarterly, 46, 280-305.

Britt, C. L. (2000). Health consequences of criminal victimization. International Review of Victimology, 8, 63-73. 
Broidy, L. M., Nagin, D. S., Tremblay, R. E., Bates, J. E., Brame, B., Dodge, K. A., et al. (2003). Developmental trajectories of childhood disruptive behaviors and adolescent delinquency: A six-site, crossnational study. Developmental Psychology, 39, 222-245.

Capaldi, D. M., \& Stoolmiller, M. (1999). Co-occurrence of conduct problems and depressive symptoms in early adolescent boys: III. Prediction to young adult adjustment. Development and Psychopathology, $11,59-84$.

Carlin, J. B., Wolfe, R., Brown, C. H., \& Gelman, A. (2001). A case study on the choice, interpretation, and checking of multilevel models for longitudinal binary outcomes. Biostatistics, 2, 397-416.

Cohen, M. A., \& Miller, T. R. (1998). The cost of mental health care for victims of crime. Journal of Interpersonal Violence, 13, 93-110.

Coie, J., Terry, R., Lenox, K., \& Lochman, J. (1995). Childhood peer rejection and aggression as predictors of stable patterns of adolescent disorder. Development and Psychopathology, 7, 697-713.

Crijnen, A. A. M., Feehan, M., \& Kellam, S. G. (1998). The course and malleability of reading achievement in elementary school: The application of growth curve modeling in the evaluation of a mastery learning intervention. Learning and Individual Differences, 10, 137-157.

Curran, P. J., Muthén, B. O., \& Harford, T. C. (1998). The influence of changes in marital status on developmental trajectories of alcohol use in young adults. Journal of Studies on Alcohol, 59, 647-658.

Deater-Deckard, K. (2001). Annotation: Recent research examining the role of peer relationships in the development of psychopathology. Journal of Child Psychology and Psychiatry and Allied Disciplines, 42, $565-579$.

Dolan, L. J., Kellam, S. G., Brown, C. H., Werthamer-Larsson, L., Rebok, G. W., Mayer, L. S., et al. (1993). The short-term impact of two classroom-based preventive interventions on aggressive and shy behaviors and poor achievement. Journal of Applied Developmental Psychology, 14, 317-345.

Eme, R. F., \& Kavanaugh, L. (1995). Sex differences in conduct disorder. Journal of Clinical Child Psychology, 24, 406-426.

Ensminger, M. E., Forrest, C. B., Riley, A. W., Kang, M., Green, B. F., Starfield, B., \& Ryan, S. A. (2000). The validity of measures of socioeconomic status of adolescents. Journal of Adolescent Research, 15, 392-419.

Fergusson, D. M., \& Horwood, L. J. (2002). Male and female offending trajectories. Development and Psychopathology, 14, 159-177.

French, D. C., Conrad, J., \& Turner, T. M. (1995). Adjustment of antisocial and nonantisocial rejected adolescents. Development and Psychopathology, 7, 857-874.

Hanson, W. B., Tobler, N. S., \& Graham, J. W. (1990). Attrition in substance abuse prevention research: A meta-analysis of 85 longitudinally followed cohorts. Evaluation Review, 14, 677-685.

Haselager, G. J. T., Van Lieshout, C. F. M., Riksen-Walraven, J. M. A., Cillessen, A. H. N., \& Hartup, W. W. (2002). Heterogeneity among peer-rejected boys across middle childhood: Developmental pathways of social behavior. Developmental Psychology, 38, 446-456.

Hektner, J. M., August, G. J., \& Realmuto, G. M. (2000). Patterns and temporal changes in peer affiliation among aggressive and nonaggressive children participating in a summer school program. Journal of Clinical Child Psychology, 29, 603-614.

Henggeler, S. W., Schoenwald, S. K., Borduin, C. M., Rowland, M. D., \& Cunningham, P. B. (1998). Multisystemic treatment of antisocial behavior in children and adolescents. New York: Guilford Press.

Jensen, P. S., Martin, D., \& Cantwell, D. P. (1997). Comorbidity in ADHD: Implications for research, practice, and DSM-V. Journal of the American Academy of Child and Adolescent Psychiatry, 36, 1065-1079.

Keenan, K., \& Shaw, D. (1997). Developmental and social influences on young girls' early problem behavior. Psychological Bulletin, 121, 95113.

Kellam, S. G., Werthamer-Larsson, L., Dolan, L. J., Brown, C. H., Mayer,
L. S., Rebok, G. W., et al. (1991). Developmental epidemiologicallybased preventive trials: Baseline modeling of early target behaviors and depressive symptoms. American Journal of Community Psychology, 19, 563-584.

Kessler, R. C., McGonagle, K. A., Zhao, S., Nelson, C. B., Hughes, M., Eshleman, S., et al. (1994). Lifetime and 12-month prevalence of DSMII-R psychiatric disorders in the United States: Results from the National Comorbidity Survey. Archives of General Psychiatry, 51, 8-19.

Kilgore, K., Snyder, J., \& Lentz, C. (2000). The contribution of parental discipline, parental monitoring, and school risk to early-onset conduct problems in African American boys and girls. Developmental Psychology, 36, 835-845.

Krueger, R. F., Caspi, A., Moffitt, T. E., \& Silva, P. A. (1998). The structure and stability of common mental disorders (DSM-III-R): A longitudinal-epidemiological study. Journal of Abnormal Psychology, 107, 216-227.

Lahey, B. B., McBurnett, K., \& Loeber, R. (2000). Are attention-deficit/ hyperactivity disorder and oppositional defiant disorder developmental precursors to conduct disorder? In A. J. Sameroff \& M. Lewis (Eds.), Handbook of developmental psychopathology (2nd ed., pp. 431-446). New York: Plenum Press.

Lambert, E. W., Wahler, R. G., Andrade, A. R., \& Bickman, L. (2001). Looking for the disorder in conduct disorder. Journal of Abnormal Psychology, 110, 110-123.

Lewin, L. M., Davis, B., \& Hops, H. (1999). Childhood social predictors of adolescent antisocial behavior: Gender differences in predictive accuracy and efficacy. Journal of Abnormal Child Psychology, 27, 277292.

Lewinsohn, P. M., Hops, H., Roberts, R. E., Seeley, J. R., \& Andrews, J. A. (1993). Adolescent psychopathology: I. Prevalence and incidence of depression and other DSM-III-R disorders in high school students. Journal of Abnormal Psychology, 102, 133-144.

Little, R. J. (1995). Modeling the dropout mechanism in repeated-measures studies. Journal of the American Statistical Association, 90, 1112-1121.

Loeber, R., Burke, J. D., Lahey, B. B., Winters, A., \& Zera, M. (2000). Oppositional defiant and conduct disorder: A review of the past 10 years, part I. Journal of the American Academy of Child and Adolescent Psychiatry, 39, 1468-1484.

Loeber, R., Green, S. M., Keenan, K., \& Lahey, B. B. (1995). Which boys will fare worse? Early predictors of the onset of conduct disorder in a six-year longitudinal study. Journal of the American Academy of Child and Adolescent Psychiatry, 34, 499-509.

Loeber, R., \& Hay, D. (1997). Key issues in the development of aggression and violence from childhood to early adulthood. Annual Review of Psychology, 48, 371-410.

Loeber, R., Keenan, K., \& Zhang, Q. (1997). Boys' experimentation and persistence in developmental pathways toward serious delinquency. Journal of Child and Family Studies, 6, 321-357.

Loeber, R., \& Stouthamer-Loeber, M. (1998). Development of juvenile aggression and violence: Some common misconceptions and controversies. American Psychologist, 53, 242-259.

Loeber, R., Wei, E., Stouthamer-Loeber, M., Huizinga, D., \& Thornberry, T. P. (1999). Behavioral antecedents to serious and violent offending: Joint analyses from the Denver Youth Survey, Pittsburgh Youth Study, and the Rochester Youth Development Study. Studies on Crime and Crime Prevention, 8, 245-263.

Loeber, R., Wung, P., Keenan, K., Giroux, B., Stouthamer-Loeber, M., Van Kammen, W. B., \& Maughan, B. (1993). Developmental pathways in disruptive child behavior. Development and Psychopathology, 5, 103-133.

Magnusson, D. (1998). The logic and implications of a person-oriented approach. In R. B. Cairns, L. R. Bergman, \& J. Kagan (Eds.), Methods and models for studying the individual (pp. 33-64). Thousand Oaks, CA: Sage. 
Maughan, B., Pickles, A., Rowe, R., Costello, E. J., \& Angold, A. (2000). Developmental trajectories of aggressive and nonaggressive conduct problems. Journal of Quantitative Criminology, 16, 199-221.

Maughan, B., \& Rutter, M. (1998). Continuities and discontinuities in antisocial behavior from childhood to adult life. In T. H. Ollendick \& R. J. Prinz (Eds.), Advances in clinical child psychology (Vol. 20, pp. 1-47). New York: Plenum Press.

McCord, J. (1983). A longitudinal study of aggression and antisocial behavior. In K. T. Van Dusen \& S. A. Mednick (Eds.), Studies of crime and delinquency (pp. 269-275). Boston: Kluwer-Nijhoff.

Moffitt, T. E. (1990). Juvenile delinquency and attention deficit disorder: Boys' developmental trajectories from age 3 to 15 . Child Development, 61, 893-910.

Moffitt, T. E. (1993). Adolescent-limited and life-course-persistent antisocial behavior: A developmental taxonomy. Psychological Review, 100, 674-701.

Moffitt, T. E., \& Caspi, A. (2001). Childhood predictors differentiate life-course-persistent and adolescence-limited antisocial pathways among males and females. Development and Psychopathology, 13, 355375 .

Moffitt, T. E., Caspi, A., Harrington, H., \& Milne, B. J. (2002). Males on the life-course-persistent and adolescence-limited antisocial pathways: Follow-up at age 26 years. Development and Psychopathology, 14, 179-207.

Moran, P. (1999). The epidemiology of antisocial personality disorder. Social Psychiatry and Psychiatric Epidemiology, 34, 231-242.

Muthén, B. (2000). Methodological issues in random coefficient growth modeling using a latent variable framework: Applications to the development of heavy drinking in ages 18-37. In J. S. Rose, L. Chassin, C. Presson, \& J. Sherman (Eds.), Multivariate applications in substance use research: New methods for new questions (pp. 113-140). Mahwah, NJ: Erlbaum.

Muthén, B., Brown, C. H., Masyn, K., Jo, B., Khoo, S. T., Yang, C. C., et al. (2002). General growth mixture modeling for randomized preventive interventions. Biostatistics, 3, 459-475.

Muthén, B., \& Muthén, L. K. (2000). Integrating person-centered and variable-centered analyses: Growth mixture modeling with latent trajectory classes. Alcoholism: Clinical and Experimental Research, 24, 1-10.

Muthén, B., \& Shedden, K. (1999). Finite mixture modeling with mixture outcomes using the EM algorithm. Biometrics, 6, 463-469.

Muthén, L. K., \& Muthén, B. O. (1998). Mplus users guide. Los Angeles, CA: Muthén and Muthén.

Nagin, D. S. (1999). Analyzing developmental trajectories: A semiparametric, group-based approach. Psychological Methods, 4, 139-157.

Nagin, D., \& Tremblay, R. E. (1999). Trajectories of boys' physical aggression, opposition, and hyperactivity on the path to physically violent and nonviolent juvenile delinquency. Child Development, 70, $1181-1196$.

New, M., \& Berliner, L. (2000). Mental health service utilization by victims of crime. Journal of Traumatic Stress, 13, 693-707.

Olsen, M. K., \& Schafer, J. L. (2001). A two-part random effects model for semicontinuous longitudinal data. Journal of the American Statistical Association, 96, 730-745.

Patterson, G. R. (1982). Coercive family processes (Vol. 3). Eugene, OR: Castalia.

Patterson, G. R. (1996). Some characteristics of a developmental theory for early-onset delinquency. In M. F. Lenzenweger \& J. J. Haugaard (Eds.), Frontiers of developmental psychopathology (pp. 81-124). New York: Oxford University Press.

Patterson, G. R., DeBaryshe, B. D., \& Ramsey, E. (1989). A developmental perspective on antisocial behavior. American Psychologist, 44, 329335.

Patterson, G. R., Forgatch, M. S., Yoerger, K. L., \& Stoolmiller, M. (1998).
Variables that initiate and maintain an early-onset trajectory for juvenile offending. Development and Psychopathology, 10, 531-547.

Patterson, G. R., Reid, J. B., \& Dishion, T. J. (1992). A social learning approach. IV: Antisocial boys. Eugene, OR: Castalia.

Petras, H., Chilcoat, H., Leaf, P., Ialongo, N., Kellam, S., \& Poduska, J. (2002, May). How early can we predict violent juvenile arrest in boys based on teacher ratings of aggression? Sensitivity/specificity in growth curve modeling. Paper presented at the annual meeting of the Society for Prevention Research, Seattle, WA.

Poe-Yamagata, E., \& Jones, M. A. (2000, April). And justice for some. Washington, DC: National Council on Crime and Delinquency. (Electronic version retrieved August 27, 2002, from http://www. buildingblocksforyouth.org/justiceforsome/jfs.html)

Raudenbush, S. W. (2000). Comparing personal trajectories and drawing causal inferences from longitudinal data. Annual Review of Psychology, 52, 501-525.

Reiger, D. A., Farmer, M. E., Rae, D. S., \& Myers, J. K. (1993). Onemonth prevalence of mental disorders in the United States and sociodemographic characteristics: The Epidemiologic Catchment Area program. Acta Psychiatrica Scandinavica, 88, 35-47.

Robinson, F., \& Keithley, J. (2000). The impacts of crime on health and health services: A literature review. Health, Risk, and Society, 2, 253266.

Samaan, R. A. (2000). The influence of race, ethnicity, and poverty on the mental health of children. Journal of Health Care for the Poor and Underserved, 11, 100-110.

Sandler, I. N., Tein, J. Y., Mehta, P., Wolchik, S., \& Ayers, T. (2000). Coping efficacy and psychological problems of children of divorce. Child Development, 71, 1099-1118.

Saris, W. E., Satorra, A., \& Soerbom, D. (1987). The detection and correction of specification errors in structural equation models. In C. C. Clogg (Ed.), Sociological methodology 1987 (pp. 105-129). Washington, DC: American Sociological Association.

Satterfield, J. H., \& Schell, A. (1997). A prospective study of hyperactive boys with conduct problems and normal boys: Adolescent and adult criminality. Journal of the American Academy of Child and Adolescent Psychiatry, 36, 1726-1735.

Schafer, J. L., \& Graham, J. W. (2002). Missing data: Our view of the state of the art. Psychological Methods, 7, 147-177.

Schwartz, D. (2000). Subtypes of victims and aggressors in children's peer groups. Journal of Abnormal Child Psychology, 28, 181-192.

Schwartz, G. (1978). Estimating the dimension of a model. The Annals of Statistics, 6, 461-464.

Sclove, L. S. (1987). Application of model-selection criteria to some problems in multivariate analysis. Psychometrika, 52, 333-343.

Shaw, D. S., Gilliom, M., Ingoldsby, E. M., \& Nagin, D. S. (2003). Trajectories leading to school-age conduct problems. Developmental Psychology, 39, 189-200.

Snyder, H. N., \& Sickmund, M. (1999). Juvenile offenders and victims: 1999 national report. Washington, DC: National Center for Juvenile Justice.

Soerbom, D. (1989). Model modification. Psychometrika, 54, 371-384.

Thompson, K. M., Wonderlich, S. A., Crosby, R. D., \& Mitchell, J. E. (1999). The neglected link between eating disturbances and aggressive behavior in girls. Journal of the American Academy of Child and Adolescent Psychiatry, 38, 1277-1284.

Tiet, Q. Q., Wasserman, G. A., Loeber, R., McReynolds, L. S., \& Miller, L. S. (2001). Developmental and sex differences in types of conduct problems. Journal of Child and Family Studies, 10, 181-197.

Tolan, P. H., \& Gorman-Smith, D. (1998). Development of serious, violent, and chronic offenders. In R. Loeber \& D. Farrington (Eds.), Never too early, never too late: Serious, violent, and chronic juvenile offenders (pp. 68-85). Beverly Hills, CA: Sage.

Turner, R. J., \& Gil, A. G. (2002). Psychiatric and substance disorders in 
South Florida: Racial/ethnic and gender contrasts in a young adult cohort. Archives of General Psychiatry, 59, 43-50.

U. S. Public Health Service. (2001). Mental health: Culture, race, and ethnicity. A supplement to Mental health: A report of the Surgeon General. Rockville, MD: U. S. Department of Health and Human Services, Office of the Surgeon General, Substance Abuse and Mental Health Services Administration, Center for Mental Health Services, National Institutes of Health, National Institute of Mental Health.

Werthamer-Larsson, L., Kellam, S. G., \& Wheeler, L. (1991). Effect of first-grade classroom environment on child shy behavior, aggressive behavior, and concentration problems. American Journal of Community Psychology, 19, 585-602.
White, H. R., Xie, M., Thompson, W., Loeber, R., \& Stouthamer-Loeber, M. (2001). Psychopathology as a predictor of adolescent drug use trajectories. Psychology of Addictive Behaviors, 15, 210-218.

Zimmerman, R. S., Khoury, E. L., Vega, W. A., \& Gil, A. G. (1995). Teacher and parent perceptions of behavior problems among a sample of African-American, Hispanic, and non-Hispanic White students. American Journal of Community Psychology, 23, 181-197.

Received August 9, 2002

Revision received June 6, 2003

Accepted June 6, 2003

\section{Call for Nominations: Rehabilitation Psychology}

The APA Publications and Communications (P\&C) Board has opened nominations for the editorship of Rehabilitation Psychology for the years 2006-2011. Bruce Caplan, PhD. is the incumbent editor.

Candidates should be members of APA and should be available to start receiving manuscripts in early 2005 to prepare for issues published in 2006. Please note that the P\&C Board encourages participation by members of underrepresented groups in the publication process and would particularly welcome such nominees. Self-nominations are also encouraged.

Rehabilitation Psychology will transition from a division publication to an "all APA" journal in 2006, and the successful candidate will be involved in making suggestions to the P\&C Board and APA Journals staff about the transition process.

Gary R. VandenBos, PhD, and Mark Appelbaum, PhD, have been appointed as cochairs for this search.

To nominate candidates, prepare a statement of one page or less in support of each candidate. Address all nominations to

Rehabilitation Psychology Search Committee

Karen Sellman, Search Liaison

Room 2004

American Psychological Association

750 First Street, NE

Washington, DC 20002-4242

The first review of nominations will begin December 8, 2003. The deadline for accepting nominations is December 15, 2003. 